\title{
Dance screening practices in dance companies, dance schools and university dance programmes: An international survey of current practices
}

\section{Ross Armstrong*}

\section{${ }^{*}$ Correspondence}

Ross Armstrong Department of Sport and Physical Activity, Sports Injuries Research Group, Edge Hill University, Ormskirk, Lancashire, L39 4QP, England. Email:armsross@edgehill.ac.uk Telephone: (+44) 01695584246

Received: Sep 11, 2018

Accepted: Jan 4, 2019

Published: Jan 18, 2019

(c) Ross Armstrong, 2019; licensee OA Journal of Clinical Case Reports. This is an Open Access article distributed under the terms of the Creative Commons Attribution License (http:// creativecommons.org/licenses/by/4.0), which permits unrestricted use, distribution, and reproduction in any medium, provided the original work is properly credited.

\begin{abstract}
Background: Dance performance requires the combination of both athletic and artistic demands. The health and well-being of dancers is of paramount importance, and one intervention that has been used to manage their health and performance is screening. There is a need to determine current screening practices to aid the management of dancers.
\end{abstract}

Methods: The Bristol online survey was used to determine screening practices in dance companies/schools and university dance programmes. The survey was available online between April 2018 and September 2018 and consisted of 39 questions which were divided into the following sections: (1) screening details, (2) physical fitness and joint screening, (3) injury screening, (4) dance specific movement screening, (5) health screening. Respondents included those individuals involved in dance screening.

Results: A total of 32 individuals participated in the study with physiotherapists and dance teachers most prevalent. Injury prevention (62.5\%) and self-management (62.5\%) were the most common aims of screening. Dancer screening occurred in a non-fatigued state in $90.63 \%$ of dancers. Flexibility (95.75\%) was physical fitness component and the feet the most assessed the most commonly assessed joint (87.5\%). Passive turnout (62.5\%) and demi-plié (62.5\%) were the most commonly assessed dance specific movements. Previous injury (87.5\%) had the highest prevalence of general health questioning. Cardiovascular screening was performed by $21.88 \%$ of respondents and the Star Excursion Balance Test (34.38\%) was the most commonly used movement screening tool. Hypermobility was screened by $75 \%$ of respondents and $28.13 \%$ of respondents used psychometric tests.

Conclusion: Physiotherapists and dance teachers were most frequently involved in screening, and the main aims were to improve the dancers health and well-being. There may be a need to consider the potential influence of acute fatigue on screening and a greater assessment of the strength, aerobic fitness and speed is required. Passive and active turnout were frequently screened and may be important in identifying potential injury risk. Cardiac and psychometric screening was limited and may require greater consideration.

Keywords: Dance screening, Injury prevention, Career longevity, Flexibility, Passive turnout, Cardiovascular screening, Star Excursion Balance Test, Hypermobility. 


\section{Introduction}

Dance requires short sets of explosive movements requiring balance, athleticism and artistry [1], indicative of movement complexity and intensity. Due to these demands, physical attributes including strength, speed, power, agility, cardiovascular endurance, flexibility, coordination and balance contribute to effective performance. Vertical ground reaction forces increase with the intensity of the dance routine $[2,3]$ and mechanical loading increases with movement difficulty [4] and dancers are required to exceed normal anatomical range [5]. One potential consequence of these demands is injury which is a challenge for sports Medicine professionals due to its significant physical, psychological and financial impact and multifactorial nature [6]. Injuries in dance result from a complex interaction between intrinsic, extrinsic and situational variables []]. Dance screening practices are a vital component of injury prevention with a recent systematic review and meta-analysis identifying range of motion ( $R O M$ ), anthropometric data and posture, dance specific positions, hypermobility, clinical diagnostic tests, and musculoskeletal screening tools as current measurements that have been investigated as predictors of injury [7]. Injury rates range from 0.62 to 5.60 injuries/1000 hours with most injuries occurring in the lower limb $[\underline{5}, \underline{8-10}]$.

A general movement screen may lack specificity and value exists in developing screening practices that can predict the likelihood of injury to maximise the specificity and therefore ability of the test to determine injury [11]. Recent research has focussed on the potential effects of fatigue on screening performance and potential implications for injury $[12,13]$ and the influence of fatigue may require greater consideration in screening practices. In addition to injury prevention, screening has previously been used to monitor performance deficits with the Star Excursion Balance Test reported to be a predictor of functional turnout angle [14] and used to assess proprioceptive training [15]. The implementation of effective injury screening tools could have positive physical and psychological impact for dancers by allowing participation with reduced injury risk. Traditionally within dance "screening" has sometimes been used as a term to describe the selection of dancers following an assessment of their performance at an audition. This study prefers to consider the term "screening" in a musculoskeletal and physical health domain. Currently it is unclear the extent to which dance companies and university dance programmes are performing screening of dancers prior to participation. Furthermore the demands of dance are varied e.g. ballet requires partner lifting and tap dancing utilises the lower extremity as a percussion instrument and such variations combined with the different levels of dance have implications for injury and performance.

The primary aim of this study was to determine current screening practices in dance companies/ schools and university dance programmes including what tests are been performed, by whom and how the information is been utilised with the aim of providing information that can potentially be used to improve dancer's health and performance. The study utilised a broad genre and level of dance and an online platform with the aim of developing an international perspective on current practices.

\section{Method}

\section{Design}

The study involved the use of an online survey utilising the Bristol on-line survey platform (www.onlinesurveys.ac.uk) which was distributed online between April 2018 and September 2018.

\section{Survey development}

The survey questions were developed by the researcher, a musculoskeletal physiotherapist with 18 years' experience of utilising screening practices in sport and dance. The researcher had received training with the Bristol online survey at their university. The questions were reviewed in a pilot study survey by five individuals involved in dance screening (physiotherapist, sports scientist, physician, biomechanist and university dance teacher) to ensure face validity and that the questions were of an appropriate level to identify any potential ambiguous questions. These five individuals agreed upon the importance of the questions subsections and that they were of interest to practitioners working with dancers. The survey was published in English and Portuguese with translation verified by a Portuguese speaking language teacher, 
physician and physiotherapist who worked in the domain of dance medicine. This translation was performed to increase international access to the survey and due to development of a Brazil-UK dance network which was able to assist with translation and the dissemination of the survey.

\section{Participants}

All participants were aged over 18 and volunteered to participate in the study. The term "respondents" will be used to identify those who completed the survey and "responses" was used to define the number of answers to a particular question. The demographics of the respondents is reported in table 1. The survey aimed to recruit individuals who potentially might be involved in dance screening namely university dance lecturers, dance teachers, physiotherapists, sports scientists, strength and conditioning coaches and any other appropriate individual. Respondents were identified using the following methods: (1) via internet searches of university dance programmes to identify individuals teaching dance programmes in the UK (63 individuals contacted via email), (2) advertisements posted via One Dance UK website, (3) Dance Science UK Facebook webpage (1,838 members), and (4) Internet search of dance companies in Europe/USA/Canada (88 companies contacted). Potential contacts were also provided via dance networks such as the Brazil-UK dance network and university dance teachers and academics (12 contacts).

\section{Survey}

The survey consisted of 39 questions which were divided into the following sections: (1) screening details, (2) physical fitness and joint screening, (3) injury screening, (4) dance specific movement screening, (5) health screening. All questions allowed respondents to select an appropriate response or select the "other" option if the appropriate response was not available and provide an answer by free text. There was no time constraint on respondents to complete the survey.

\section{Ethical considerations}

All respondents completed informed consent forms and were provided with an information sheet before commencing the study. Ethical approval was granted by the University Research Ethics Committee in accord with the Helsinki Declaration of 1975.

\section{Data analysis}

Survey responses were reported as descriptive statistics (actual score and percentage) to allow an overview of current screening practices.

\section{Results}

The total survey response rate was calculated for university dance programmes for which 3/63 (4.76\%) respondents indicated they were involved in screening and would complete the survey. The aim of the survey was not to report how many dance companies/schools and university were not screening but what was been performed. Therefore from these non-responders it cannot be presumed that they do not perform screening. For the dance companies contacted via email, 2/88 (2.27\%) indicated they would complete the survey. From the other methods of recruitment, it was not possible to calculate response rate due to anonymity. A total of 32 respondents completed the study with physiotherapists, $14(43.75 \%)$ the most prominent profession. Respondents were from the UK, Brazil, Canada, USA, Slovenia, Australia, New Zealand and Ireland.

Table 1: Demographics of survey respondents and those involved in the screening process

\begin{tabular}{|l|l|}
\hline Profession & $\begin{array}{l}\text { Involved in the } \\
\text { screening process }\end{array}$ \\
\hline Physiotherapist 14 (43.75\%) & Physiotherapist 19 (38\%) \\
\hline Academic researcher 2 (6.25\%) & Sports Scientist 9 (18\%) \\
\hline Sports Therapist 1 (3.13\%) & Dance teacher 11 (22\%) \\
\hline $\begin{array}{l}\text { Strength and conditioning } \\
\text { coach 2 (6.25\%) }\end{array}$ & Physician 5 (10\%) \\
\hline Dance teacher 7 (21.88\%) & Sports Therapist 1 (2\%) \\
\hline Physician 2 (6.25\%) & Dance scientist 1 (2\%) \\
\hline Ballet school director 1 (3.13\%) & Nurse 1 (2\%) \\
\hline Podiatrist 1 (3.13\%) & $\begin{array}{l}\text { Dance science researcher 1 } \\
(2 \%)\end{array}$ \\
\hline Scientist 1 (3.13\%) & Pilates teacher 1 (2\%) \\
\hline Pilates teacher 1 (3.13\%) & Podiatrist 1 (2\%) \\
\hline
\end{tabular}




\section{Screening details}

General aims of screening

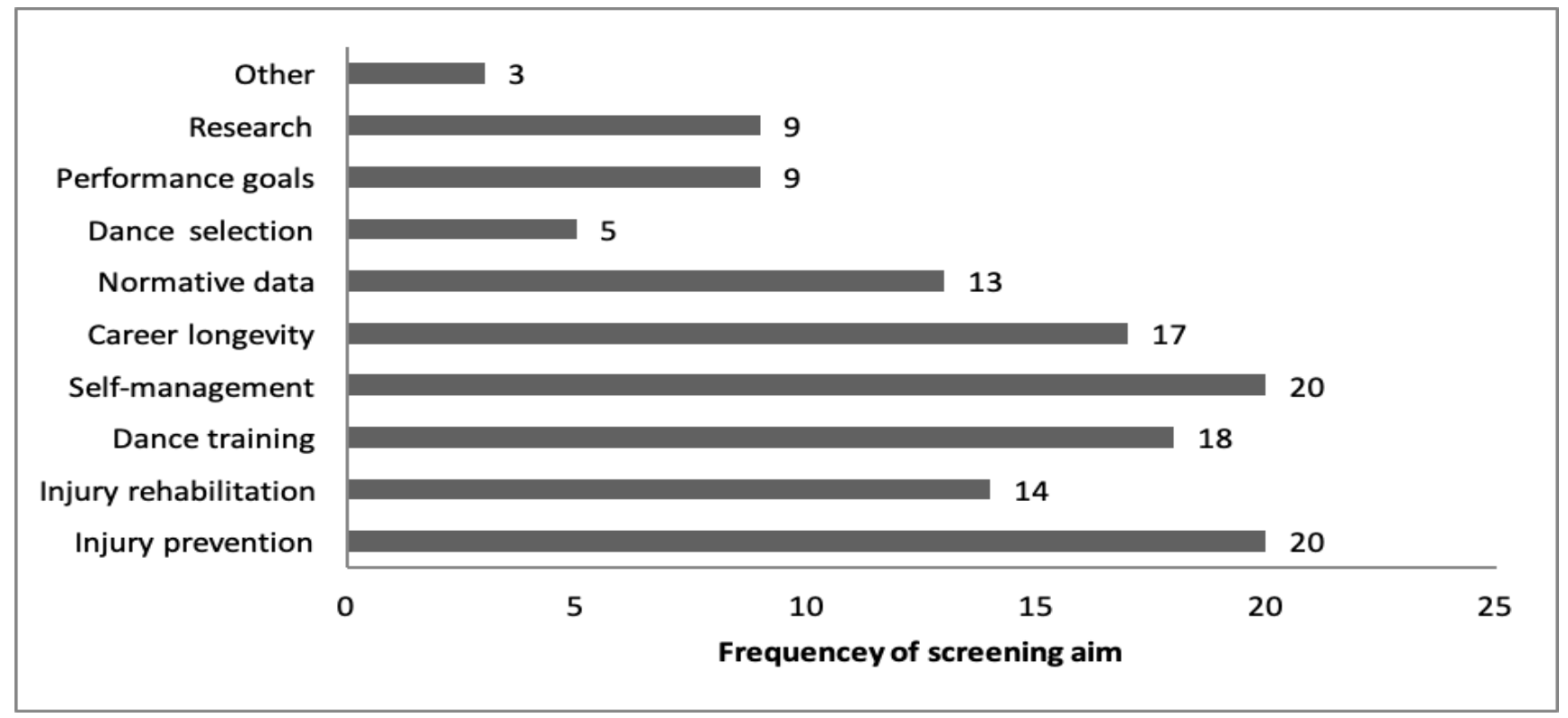

Figure 1. Reports the general aims of screening identified by respondents.

Figure 1 Screening aims

The most prominent aims of screening was injury prevention (20/128 responses, $15.6 \%)$, selfmanagement of fitness and injury among the dancers (20/128 responses, $15.6 \%$ ), effective dance training (18/128 responses, $14.1 \%)$, increase career longevity (17/128 responses, $13.3 \%)$, injury rehabilitation (14/128 responses, $10.9 \%$ ) and to provide normative data for performance monitoring (13/128 responses, $10.2 \%)$. Other aims that were given were to "remove the stigma of seeking healthcare", "to connect with clients" and to get clients "onside" with screening.

\section{Frequency of screening}

Respondents reported that the screening process occurred monthly, 5 respondents (15.63\%), 1-3 months, 6 respondents (18.75\%), 4-6 months, 2 respondents (6.25\%), 7-12 months, 11 respondents (34.38\%), more than 12 months, 3 respondents (9.38\%) and other, 5 respondents (15.63\%) which included weekly, 1 respondent (3.13\%) and responses of "depends on the clinical situation", "when the students have an injury", "during auditions", "dancers self-select", "following injury every 4 to 6 weeks" were also recorded.
Involvement in the screening process

Table 1 contains information regarding who is involved in the screening process.

\section{Fatigue status}

Twenty-nine respondents (90.63\%) performed screening in a non-fatigued state and 3 respondents (9.38\%) performed screening in a fatigued state.

\section{Feedback and intervention}

Twenty-nine respondents (90.63\%) provided dancers with feedback and three respondents (9.38\%) did not provide dancers with feedback on their results. Twenty respondents (62.5\%) provided an intervention programme and 12 respondents (37.5\%) did not based upon the screening results.

\section{Physical fitness and joint screening}

Table 2 and table 3 report physical fitness components that respondents identified as part of the screening process. Flexibility, 30 respondents (95.75\%) was the most commonly assessed component and speed, 8 respondents (25\%) the least considered physical fitness component. The one leg stand, 23 respondents (71.88\%) and straight leg raise, 22 respondents $(68.75 \%)$ were the individual components that were most prevalent in physical fitness screening. 
Table 2: Strength, flexibility and balance components of the screening process

\begin{tabular}{|c|c|c|}
\hline Strength & Flexibility & Balance \\
\hline Calf raises 19 (59.38\%) & Straight leg raise 22 (68.75\%) & One leg stand $23(71.88 \%)$ \\
\hline Isokinetic dynamometer 5 (15.63\%) & Thomas Test 11 (34.38\%) & Tekscan 1 (3.13\%) \\
\hline Adductor squeeze 2 (6.25\%) & Toe touch $12(37.50 \%)$ & One leg stand eyes closed 1 (3.13\%) \\
\hline $\begin{array}{l}\text { Grip strength (hand held dynamometer) } 3 \\
(9.38 \%)\end{array}$ & Obers test 6 (18.75\%) & Star Excursion Balance Test 1 (3.13\%) \\
\hline Manual muscle testing 1 (3.13\%) & Knee to wall test $3(9.38 \%)$ & Single leg squat 1 (3.13\%) \\
\hline $\begin{array}{l}\text { Observing functional movement patterns } 1 \\
(3.13 \%)\end{array}$ & Internal/external hip rotation 1 (3.13\%) & Single leg rise 1 (3.13\%) \\
\hline 10 RPM leg press 1 (3.13\%) & Ballet moves (e.g. abraseque) 1 (3.13\%) & $\begin{array}{l}\text { One leg knee bend in parallel and turnout } \\
1(3.13 \%)\end{array}$ \\
\hline $\begin{array}{l}\text { Hamstring curls/quadriceps extensions } 1 \\
(3.13 \%)\end{array}$ & Beighton score 1 (3.13\%) & $\begin{array}{l}\text { Modified Rhomberg, one leg closed } 1 \\
(3.13 \%)\end{array}$ \\
\hline McGill's Strength test (trunk) 1 (3.13\%) & Splits $1(3.13 \%)$ & Aeroplane sequence 1 (3.13\%) \\
\hline $\begin{array}{l}\text { Countermovement jump on bilateral force plate } \\
1(3.13 \%)\end{array}$ & $\begin{array}{l}\text { Goniometer measurement with the hip } \\
\text { in flexion and external rotation } 1 \\
(3.13 \%)\end{array}$ & $\begin{array}{l}\text { Balance time in passé or arabesque } 1 \\
(3.13 \%)\end{array}$ \\
\hline Countermovement jump 1 (3.13\%) & $\begin{array}{l}\text { Shoulder flexibility (circumduction) } 1 \\
(3.13 \%)\end{array}$ & $\begin{array}{l}\text { Ballet specific tendu en croix in centre } 1 \\
(3.13 \%)\end{array}$ \\
\hline Push up test 1 (3.13\%) & Forward bend sitting 1 (3.13\%) & - \\
\hline Seated shoulder press 1 (3.13\%) & - & - \\
\hline Side plank to failure 1 (3.13\%) & - & - \\
\hline Repeated single leg squat 1 (3.13\%) & - & - \\
\hline Ballet specific movements 1 (3.13\%) & - & - \\
\hline Not tested 10 (31.25\%) & Not tested 2 (6.25\%) & Not tested 6 (18.75\%) \\
\hline
\end{tabular}

Abbreviations: RPM: Rep max 
Table 3: Aerobic fitness, speed and power components of the screening process

\begin{tabular}{|c|c|c|}
\hline Aerobic fitness & Speed & Power \\
\hline Multistage fitness test 3 (9.38\%) & 10 metre sprint test $2(6.25 \%)$ & Counter movement jump 8 (25\%) \\
\hline Dance Aerobic Fitness Test (Ballet) 5 (15.63\%) & 30 metre sprint test $4(12.50 \%)$ & Vertical jump 15 (46.87\%) \\
\hline $\begin{array}{l}\text { Dance Aerobic Fitness Test (Contemporary) } 8 \\
(25 \%)\end{array}$ & T-test $3(9.38 \%)$ & Drop test $1(3.13 \%)$ \\
\hline 3 minute Harvard Step test 2 (6.25\%) & $60 m$ sprint $1(3.13 \%)$ & Repetitive jump test 1 (3.13\%) \\
\hline VO2 max treadmill test 1 (3.13\%) & $600 m$ sprint $1(3.13 \%)$ & $\begin{array}{l}\text { Observation of eccentric control with sauté/ } \\
\text { single leg hop } 1(3.13 \%)\end{array}$ \\
\hline $\begin{array}{l}3 \text { minute step test with accelerated bpm to } 1121 \\
(3.13 \%)\end{array}$ & - & 1 RPM 1 (3.13\%) \\
\hline Class situation $1(3.13 \%)$ & - & 3 RPM hop (3.13\%) \\
\hline- & - & $\begin{array}{l}\text { Repeated hop test ( } 5 \text { single leg max } \\
\text { repeatedly) } 1(3.13 \%)\end{array}$ \\
\hline - & - & $\begin{array}{l}\text { Movement Competency Screening Tool } 1 \\
(3.13 \%)\end{array}$ \\
\hline - & - & $\begin{array}{l}\text { Video assessment of jump land control } 1 \text { (3.13 } \\
\%)\end{array}$ \\
\hline - & - & Dance specific jumps 1 (3.13\%) \\
\hline Not tested 15 (46.88\%) & Not tested 24 (75\%) & Not tested 7 (21.88\%) \\
\hline
\end{tabular}

Abbreviations: VO2 max: Maximum aerobic capacity, BPM: Beats per minute, RPM: Rep max

\section{Orthopaedic assessment}

\section{Anthropometric measurements}

Twenty-three respondents (71.88\%) performed measurement of the following anthropometric measures: height, 22 respondents (68.75\%), body mass, 15 respondents (46.88\%), body mass index, 16 respondents (50\%), body composition, 11 respondents (34.38\%), 3D scan, 1 respondent (3.13\%). Nine respondents $(28.13 \%)$ did not perform anthropometric measurements.
Table 4 reports the joint measurements performed at the feet, knee, hip and spine and symmetry considerations. The feet, 28 respondents (87.5\%), hip, 26 respondents (81.25\%) and spine, 26 respondents (81.25\%) were the joints that were most prevalent during screening. Hip ROM, 22 respondents (68.75\%) and ankle ROM, 19 respondents (59.38\%) were the individual components that were most prevalent. 
Table 4: Joint and symmetry screening

\begin{tabular}{|c|c|c|c|c|}
\hline Feet & Knee & Hip & Spine & Symmetry \\
\hline Hallux valgus 11 (34.38\%) & Knee ROM 12 (37.5\%) & Hip strength 14 (43.75\%) & Lumbar ROM 13 (40.63\%) & Leg length 18 (56.25\%) \\
\hline Ankle ROM 19 (59.38\%) & $\begin{array}{l}\text { Muscle strength } 13 \\
(40.63 \%)\end{array}$ & Hip ROM 22 (68.75\%) & $\begin{array}{l}\text { Lumbar strength } 3 \\
(9.38 \%)\end{array}$ & $\begin{array}{l}\text { Upper limb symmetry } 9 \\
(28.13 \%)\end{array}$ \\
\hline $\begin{array}{l}\text { Ankle muscle strength } \\
12(37.5 \%)\end{array}$ & Genu valgum 14 (43.75\%) & Quadrants 1 (3.13\%) & $\begin{array}{l}\text { Thoracic ROM } 11 \\
(34.38 \%)\end{array}$ & $\begin{array}{l}\text { Lower limb symmetry } 8 \\
(25 \%)\end{array}$ \\
\hline Foot type $14(43.75 \%)$ & Genu varum 11 (34.38\%) & $\begin{array}{l}\text { Adductor squeeze at } 0^{\circ} \\
\text { and } 45^{\circ} 1(3.13 \%)\end{array}$ & $\begin{array}{l}\text { Thoracic strength } 6 \\
(18.75 \%)\end{array}$ & $\begin{array}{l}\text { Femoral ant/retroversion } \\
1(3.13 \%)\end{array}$ \\
\hline Big toe ROM 17 (53.13\%) & $\begin{array}{l}\text { Alignment via squat } \\
\text { assessment } 1(3.13 \%)\end{array}$ & $\begin{array}{l}\text { In ballet, external } \\
\text { rotation in retiré } 1 \text { (3.13\%) }\end{array}$ & Cervical ROM 9 (28.13\%) & - \\
\hline $\begin{array}{l}\text { Alignment and stability } \\
\text { via double and single leg } \\
\text { rises } 1(3.13 \%)\end{array}$ & $\begin{array}{l}\text { Static lower limb control } \\
\text { with squat } 1(3.13 \%)\end{array}$ & - & $\begin{array}{l}\text { Cervical strength } 2 \\
(6.25 \%)\end{array}$ & - \\
\hline $\begin{array}{l}\text { Flexor Hallucis Longus } \\
\text { length } 1(3.13 \%)\end{array}$ & $\begin{array}{l}\text { Orthopaedic tests: Ant/ } \\
\text { post draw, duck walk, } \\
\text { MCL/PCL, Thessaly } 1 \\
(3.13 \%)\end{array}$ & - & Scoliosis 18 (56.25\%) & - \\
\hline Proprioception 1 (3.13\%) & $\begin{array}{l}\text { Knee alignment in } \\
\text { parallel single leg bend } \\
\text { and demi plie on one leg } \\
2(6.25 \%)\end{array}$ & - & Hyperlordosis 9 (28.13\%) & - \\
\hline $\begin{array}{l}\text { Force plantar flexion } 1 \\
(3.13 \%)\end{array}$ & Patella mobility 2 (6.25\%) & - & Kyphosis 11 (34.38\%) & - \\
\hline $\begin{array}{l}\text { Observe rise to demi } \\
\text { pointe } 1(3.13 \%)\end{array}$ & - & - & $\begin{array}{l}\text { Spondylolisthesis } 3 \\
(9.38 \%)\end{array}$ & - \\
\hline $\begin{array}{l}3 \mathrm{~d} \text { scan longitudinal } \\
\text { measurement of the foot } \\
1(3.13 \%)\end{array}$ & - & - & $\begin{array}{l}\text { Core capacity and } \\
\text { control assessments } 1 \\
(3.13 \%)\end{array}$ & - \\
\hline $\begin{array}{l}\text { Mid tarsal joint ROM } 1 \\
(3.13 \%)\end{array}$ & - & - & Slump test $1(3.13 \%)$ & - \\
\hline Not tested $4(12.5 \%)$ & Not tested 7 (21.86\%) & Not tested $6(18.75 \%)$ & Not tested 6 (18.75\%) & Not tested $10(31.25 \%)$ \\
\hline
\end{tabular}

Abbreviations: ROM: Range of motion, MCL: Medial collateral ligament, PCL: Posterior collateral ligament

\section{Injury screening}

Injury audit, injury severity and mechanism of injury Nineteen respondents (59.38\%) collected injury audit data and 13 respondents (40.63\%) did not. Twentyfive respondents (78.13\%) asked questions regarding injury severity and mechanism of injury and 7 respondents (21.88\%) did not.

\section{Fatigue, warm up and sporting activity}

Twenty-two respondents (68.75\%) asked questions regarding overtraining and fatigue during screening and 10 respondents (31.25\%) did not. Twenty-four respondents (75\%) asked whether dancers warmed up during screening and 8 respondents (25\%) did not. Twenty-one respondents (65.62\%) recorded activity in other sporting activities during screening and 11 respondents (34.38\%) did not.

\section{Dance specific screening}

Dance genre and dance specific movements

Twenty-six respondents (81.25\%) asked questions regarding dance genre during screening and 6 respondents (18.75\%) did not. Figure 2 reports the dance specific movements that were observed with passive turnout 20 (62.5\%) and demi-plié 20 (62.5\%) most commonly assessed. 


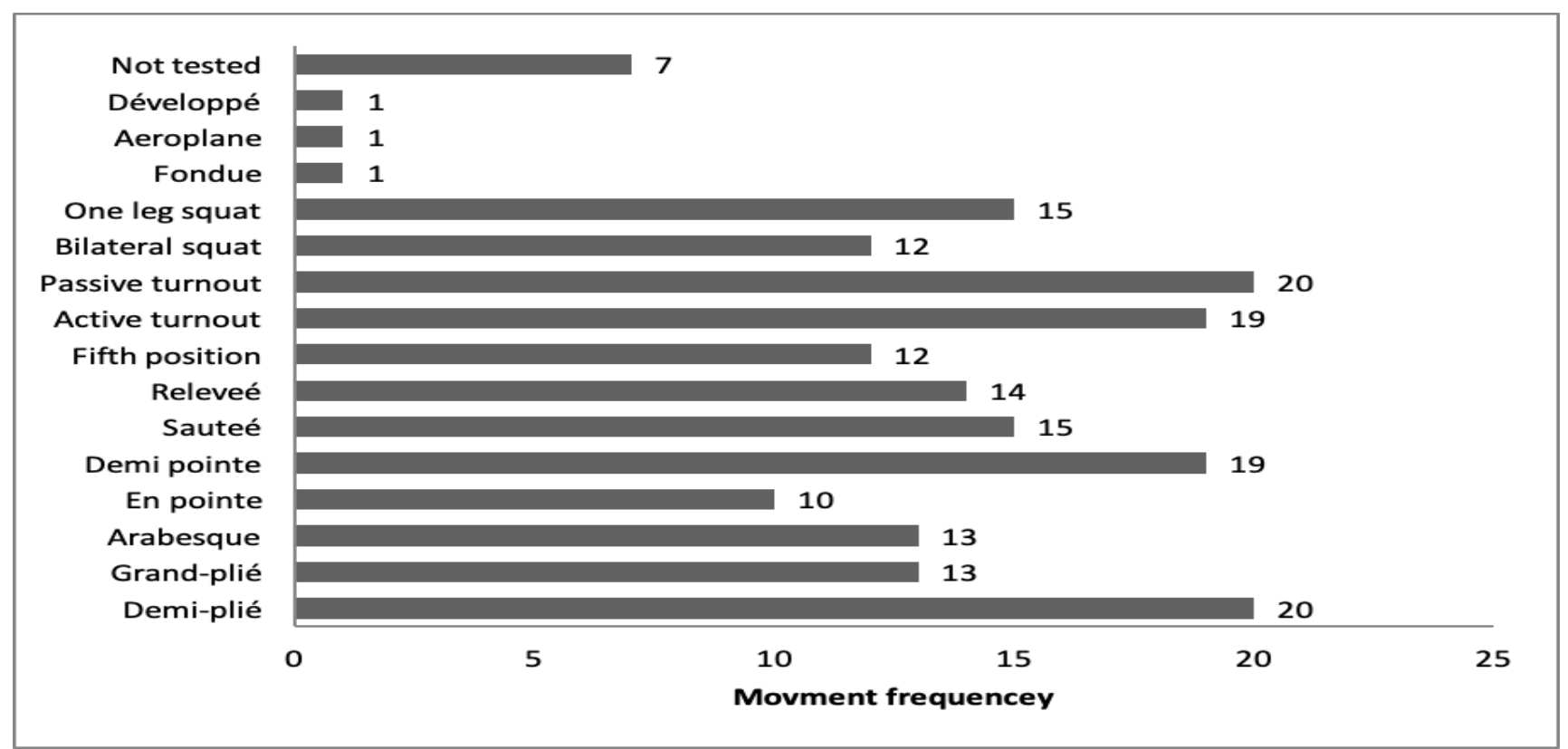

Figure 2. Dance specific movement screening

En pointe

Nineteen respondents (59.40\%) asked questions regarding what age dancers commence en pointe while 13 respondents $(40.60 \%)$ did not.

\section{Health Screening}

General health

Figure 3 reports the subject areas asked regarding general health. The most commonly assessed component was previous injury, 28 respondents (87.5\%).

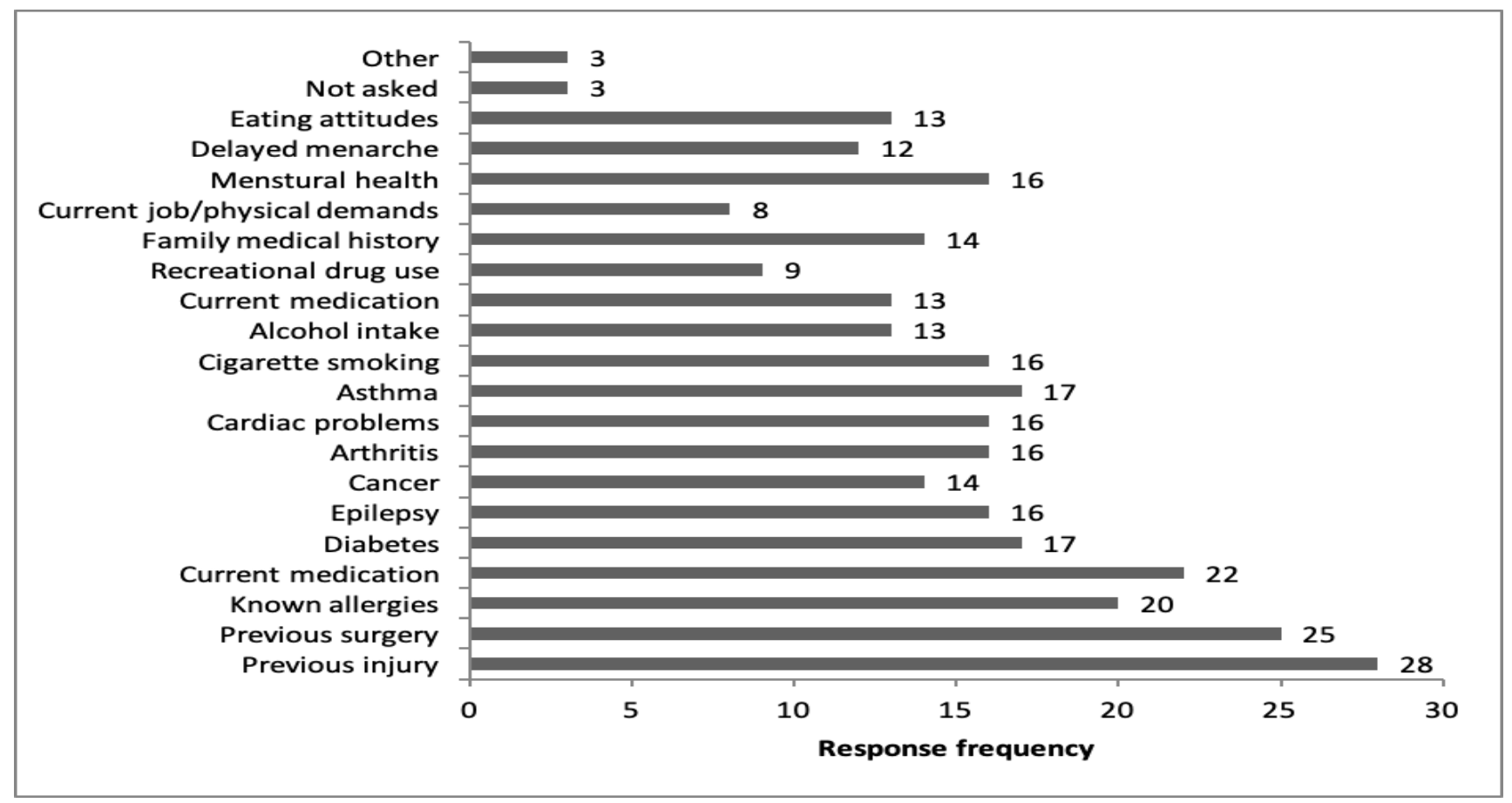

Figure 3. Dance specific movement screening 


\section{Cardiovascular screening}

Seven respondents $(21.88 \%)$ performed cardiovascular screening and 25 respondents (78.13\%) did not. When performed it was undertaken with the following frequency: 1-3 months, 1 respondent (3.13\%), 4 to 6 months, 1 respondent (3.13\%), 7 to 12 months, 2 respondents (6.25\%), more than 12 months, 3 respondents (9.38\%). Cardiac screening commences at 14 years, 2 respondents (6.25\%), at 15 years, 3 respondents $(9.38 \%)$, at the first screening $(9.38 \%), 2$ respondents (6.25\%) and one respondent (1.12\%) had an arrangement with a hospital for screening via "cardiac risk for the young".

\section{Movement screening}

The movement screening tests used by respondents is reported in figure 4. The most prevalent measurement was the Star Excursion Balance Test, 11 respondents (34.38\%).

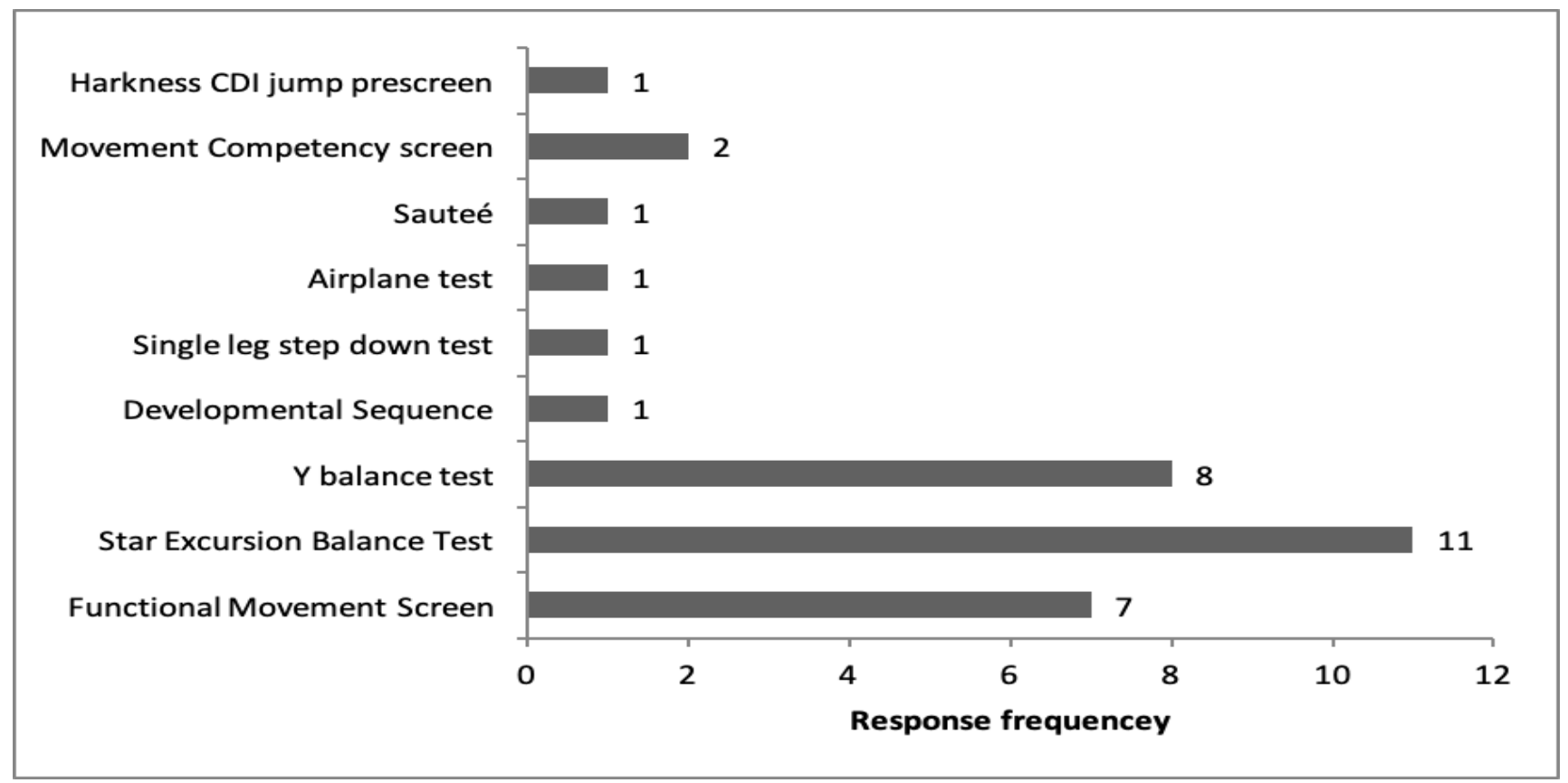

Figure 4. Movement screening tools

Abbreviations: CDI: CUNY Dance Initiative

\section{Hypermobility}

Twenty-four respondents (75\%) screened for hypermobility and 8 respondents (25\%) did not. Of those that screen for hypermobility, 20 respondents (83.33\%) used the Beighton score and 4 respondents (16.66\%) did not. Seventeen respondents used the following Beighton score cut off points: Beighton score of 2, 1 respondent (5\%), Beighton score of 4, 5 respondents (25\%), Beighton score of 5, 9 respondents (45\%), Beighton score of 6,1 respondent (5\%), Beighton score of 7, 1 respondent (5\%). 3 respondents (15\%) did not state a Beighton score cutoff.
Seventeen respondents (53.13\%) used the Brighton criteria to screen for hypermobility and fifteen respondents (46.88\%) did not.

\section{Psychology assessment}

Nine respondents $(28.13 \%)$ used psychometric tests to measure anxiety, depression and general mood state and 23 respondents (71.88\%) did not. The psychometric tests were: Dimensions of Anger Reactions (DAR) [16], 1 respondent (3.13\%), Profile of Mood States (POMS) [17], 1 respondent (3.13\%), State and Trait anxiety [18], motivation, 1 respondent (3.13\%), self-image, 1 respondent (3.13\%), personality, 1 respondent (3.13\%), values, 1 respondent (3.13\%), 6 depression screen questionnaires, 1 respondent (3.13\%) and unknown, 1 respondent (3.13\%). 


\section{Discussion}

The primary aim of this study was to determine current screening practices in dance. The study utilised a broad genre and level of dance and an online platform with the aim of developing an international perspective on current practices.

\section{Screening details}

The survey was completed by 10 different professions of which physiotherapist and dance teacher was the most prevalent. Injury prevention, self-management, dance training and career longevity were identified as the main aims of screening. These all highlight that the management of the health and well-being of the dancer is of paramount importance. Injury has considerable physical and psychological impact and its prevention follows the Van Mechelen model of injury prevention [19] which requires identification of potential risk factors before the implementation of preventative measures. This approach would increase self-management of health and dance training and hopefully impact positively on career longevity.

Screening frequency varied from weekly to more than 12 months with 7 to 12 months the most common interval (34.38\%). However, for injury prevention is it possible that screening might be advised on a more frequent basis with $37.51 \%$ of screening occurred from weekly to 3 months. Future studies may consider investigating screening frequency in relation to injury rates and performance changes. Some respondents only use screening following injury. However, this does not allow for potential injury prevention strategies to be implemented. Fatigue is the decline in force or power produced by a muscle [20] resulting in a transient decrease in muscular performance [21] and may lead to disrupted movement patterns resulting in injury [22 23]. Only $9.38 \%$ of respondents screened in a fatigue state. The effects of fatigue on screening has been found to be task specific with the movements of the Star Excursion Balance test (composite score, anterior, posterolateral, and posteromedial directions) demonstrating non-significant findings for both dominant and non-dominant legs pre and post-performance of the Dance Aerobic Fitness Test [12]. In contrast, fatigue effects were observed in elements of the Functional Movement Screen (deep squat, hurdle step non-dominant and in-line lunge non-dominant and dominant legs) pre and post- performance of the Dance Aerobic Fitness Test [13]. Therefore, there may be a need to consider potential fatigue effects during screening and the investigation of dance specific movements under the influence of fatigue may be beneficial. The majority of respondents provided dancers with feedback which could be considered best practice in allowing the dancer to take greater responsibility and formulate their own goals.

\section{Physical fitness and joint screening}

Flexibility was deemed the most important component to measure with $93.77 \%$ of respondents testing this component with the straight leg raise the most prevalent component. Strength was measured by $68.75 \%$ of respondents with calf raises the most prominent accounting for $46.34 \%$ of strength tests, while flexibility tests of the calf as assessed by the knee to wall test accounted for only $4.92 \%$ which may suggest that practitioners are not always considering the action of specific muscle groups and testing all their aspects. The relatively low value of strength testing may represent that flexibility remains the primary focus in the development of physical fitness components. Within the measurement of flexibility, a number of dance specific movements were measured by respondents including movements in parallel, turnout and arabesque which may highlight the need for dance specific movements.

Only $25 \%$ of respondents measured speed which may reflect the possibility that it is not deemed essential for performance or a lack of tests with relevance to dance performance with the 30 metre speed test and T-test [24] which also measures agility most prominent. With regard to aerobic fitness, $53.12 \%$ of respondents measured this component the reasons for this relatively low number could relate to how long the tests can potentially take and that they may impact on the performance of other tests if done on the same day or a consensus that power, balance and flexibility are more important. The Dance Aerobic Fitness Test [25] was the most prevalent aerobic test. Power was measured by $78.12 \%$ of respondents with a large variety of different tests used with the vertical jump most prominent (46.87\%). Potentially some respondents may feel that jump performance provides a measure of speed performance more appropriate to dance performance than the measurement of linear speed. 


\section{Anthropometric measurements}

Height (68.75\%) was the most commonly measured anthropometric variable and may reflect the importance of monitoring growth and along with body mass is required for body mass index calculation. Body composition was measured by $34.38 \%$ of respondents and future research may wish to clarify the methods utilised e.g. skinfold measurements, bodpod.

\section{Orthopaedic measurements}

The feet (87.5\%), hip (81.25\%), spine (81.25\%), and knee $(78.14 \%)$ were all included in screening to a similar degree which is in contrast to the findings with physical fitness. Despite the aesthetic demands of dance only $68.75 \%$ of respondents screened for symmetry. The screening of the lower limb might highlight the high prevalence of lower limb injuries associated with dance. At the ankle, the most commonly assessed were ankle ROM, big toe ROM and foot type while at the knee it was genu valgum, muscle strength and genu varum. Knee ROM was not considered as important as Ankle ROM which may reflect the importance of the ankle to dance performance. At the hip, ROM and strength were the most common measurement. This focus on ROM is supported by the findings of a systematic review [7] which identified hip ROM as a predictor of injury and this measurement was the most prevalent across the orthopaedic measurements. At the spine, scoliosis was measured with the greatest frequency and a higher prevalence of back injuries has been reported in scoliotic dancers [26]. ROM measurements at the lumbar, thoracic and cervical spine were more prevalent that strength assessment in these regions and there may be a need to consider both aspects when performing spinal assessment. All regions of the spine should be assessed due the kinetic chain and loading mechanics. The author acknowledges that in the future the shoulder, elbow and wrist should be included in questioning regarding orthopaedic measurement.

\section{Injury screening}

Injury audit, injury severity and mechanism of injury

The finding that $59.38 \%$ of respondents collected injury data and that $78.13 \%$ of respondents asked questions regarding injury severity and mechanism of injury highlights the importance of injury prevention. The majority of those who collected injury data (85\%) were physiotherapists, physicians and strength and conditioning coaches which may highlight their professional training in injury surveillance.

\section{Fatigue, warm up and sporting activity}

The finding that $68.75 \%$ of respondents asked questions regarding overtraining and fatigue during screening demonstrates an awareness that fatigue and overtraining are injury risk factors. This is in contrast, however, to the number of respondents who actually screened in a fatigued state. Currently, some respondents are not considering the acute fatigue response when screening but are aware of the influence of chronic fatigue, and the potential overuse injury risk due to cumulative fatigue stressors.

\section{Dance specific screening}

Dance genre and dance specific movements

Questions regarding dance genre during screening were prominent and may reflect an understanding of the different demands of dance genres. Dance specific movements are a prominent part (78.12\%) of the screening process and may highlight that respondents are considering the movement patterns of specific movements with the vast majority of movements from ballet. Monitoring of passive and active turnout is encouraging as these movements have been identified as a predictor of injury [?]. The measurement of one leg squat and bilateral squat is in agreement with previous research that has identified that low performers in the deep squat make gross movement errors [27] and asymmetry may result in inappropriate muscle recruitment or weight transference. Successful deep squat performance requires the coordination of stability and mobility throughout the kinetic chain [28] and weakness and/or limited mobility in the lower extremities reduce deep squat performance [29]. Furthermore deep squat performance has been identified as the primary predictor of mechanical joint loading in dancers during the Dance Aerobic Fitness Test [30].

The age of going en pointe may have importance with regard to growth plate development and determine when a dancer is ready with regard to having appropriate pelvic alignment control and 
appropriate flexibility and strength in the ankle. Dancers most commonly start pointe work around the age of 12 years and a force 12 times body weight can be experienced through the ankle and foot [31].

\section{Health screening}

A variety of themes very investigated via general health questioning and $90.62 \%$ of respondents asked questions regarding general health which highlights awareness of the need to assess general health. Unfortunately the survey did not investigate what the respondents do when they identify a potential problem (e.g. onward referral if appropriate) and this could be considered in future research. The most commonly asked questions were previous injury and surgery which relates to the main aims of screening identified. Key medical areas such diabetes epilepsy, cancer, arthritis, cardiac problems, asthma and family medical history were not as prevalent as might be expected and the reasons for this require further investigation. It may relate to some respondents who undertake screening not feeling qualified to ask these questions however it would be hoped that these questions would be asked by an appropriate individual prior to dancing commences. Eating attitudes (40.63\%), menstrual health (50\%) and delayed menarche (37.5\%) may relate to the Female athlete triad [32] and aspects of the Relative Energy Deficiency in Sports (RED-S) [33] and should be considered in screening. Menstural dysfunction and low bone mineral density can be related to dietary restrictions and low body mass associated with dancers [34, 35].

\section{Cardiovascular screening}

A total of $21.88 \%$ of respondents performed cardiovascular screening. One respondent identified that their dancers had access to cardiac screening via "Cardiac risk in the young" (www.c-r-y.org.uk) based in the UK. Screening was identified as commencing at the ages of 14 and 15 years and the majority of respondents who performed cardiac screening in this survey were professional dance companies. An analysis of sudden cardiac deaths in the USA in young athletes identified an incidence of sudden cardiac death of $0.61 / 100,000$ [36] and it might be worthwhile for dance companies/schools and university programmes currently screening to consider developing links to commence a cardiac screening programme. Future research could aim to determine what specific cardiac screening tests are been performed.

\section{Movement screening}

The most commonly performed movement screening test was the Star Excursion Balance Test (33.33\%) [37] followed by its related test the Y-balance test [38] (24.24\%). The Star Excursion Balance Test challenges dynamic postural control and requires strength, proprioception and flexibility [39] and limb gesturing movements similar to dancers pointing the targeting toe in space while maintaining balance on the stance leg [40]. However there is a possibility that the $Y$ balance test is not challenging enough for dancers due to the limited changes observed in its performance in a fatigued state [12] and dancers have enhanced balance in comparison to other groups and may demonstrate more distinct and variable kinematic strategies which facilitate performance of the SEBT [41]. The Functional Movement Screen (21.21\%) featured highly and future research may wish to ask respondents which components are most important. Other screening tests related to dance specific movements such as the sauté [느, 43].

\section{Hypermobility}

Hypermobility was screened by $75 \%$ of respondents and $83.33 \%$ used the Beighton score with cut off points of 4, 5 and 6 most prevalent in agreement with previous findings [44] however there may be a need to consider the use of lumbar flexion in scoring due to its previously highly reported prevalence in dancers [45]. The finding that $53.13 \%$ of respondents used the Brighton criteria demonstrates that respondents investigate a number of aspects of hypermobility however future research may wish to enquire whether the recently developed hypermobility spectrum [46] is been utilised. The Beighton score has previously been identified as a predictor of arthralgia and dislocation/subluxation [47] which form part of the Brighton Criteria [48] and therefore the recording of Beighton score may have value for injury prevention during screening.

\section{Psychology assessment}

Psychometric tests were used to measure anxiety, depression and general mood state and a variety of psychometric tests were used with not one test been used by more than one participant. The psychometric 
tests that were used included: DAR [16], POMS [17] and State and Trait anxiety [18]. This lack of use and consistency of psychometric tests applied may represent the fact that no psychologists were identified as been involved in screening process.

\section{Limitations}

The findings of this survey are limited to the respondents and by the level of detail provided in answers. Future research could consider a great level of free text for respondents to provide further information. When contacting potential respondents via email there is no way of knowing how many of the respondents are either not involved in screening or merely chose not to participate in the survey. A larger sample size would have been beneficial as this would potentially have allowed a comparison of screening procedures between different countries and between different dance levels.

\section{Conclusion}

The survey provided an overview of current screening practices and identified that physiotherapists and dance teachers were most frequently involved, and the main aims were to improve the dancer's health and well-being. There may be a need to consider the potential influence of acute fatigue on screening and a greater assessment of the strength, aerobic fitness and speed is required and there should be greater consideration of all aspects at a joint (e.g. strength and ROM). Passive and active turnout were frequently screened, and this may be important in identifying potential injury risk. There may be a need for certain areas of the general health section to be considered in greater depth with regard to medical conditions and those aspects related to RED-S. Cardiac and psychometric screening was limited and this might need to be considered to provide a more holistic approach to future dance screening.

\section{Acknowledgement}

The author wishes to thank Samara Silviano Pedrosa, Faculdade de Direito de Conselheiro Lafaiete, Brazil for help with Portuguese translation, Dr Izabela Lucchese Gavioli, Federal University of Rio Grande do Sul, Brazil, Derrick Brown, Radboud University, Netherlands, Dr Adriano Bittar, Universidade Estadual de Goias, Brazil, Aline Nogueria Haas, Federal University of Rio Grande Do Sul, Brazil for their opinions regarding the design of survey questions. Dr Petra Zaletel, University of Ljubljana and Erin Sanchez, One Dance UK for assistance in distribution of the survey. Thank you to all the respondents who took time to complete the survey.

\section{References}

1. Simon J, Hall E, Docherty C (2014) Prevalence of Chronic Ankle Instability and Associated Symptoms in University Dance Majors An Exploratory Study. J Dance Med Sci. 18: 178-184.

2. Ricard MD, Veatch S (1994) Effect of running speed and aerobic dance jump height on vertical ground reaction forces. J Appl Biomech. 10: 14-27.

3. Rousanoglou EN, Boudolos KD (2005) Ground reaction forces and heart rate profile of aerobic dance instructors during a low and high impact exercise programme. J Sports Med Phys Fitness. Jun;45: 162-170

4. Brogden CM, Armstrong R, Page R, et al. (2018) Use of triaxial accelerometry during the Dance Aerobic Fitness Test Considerations for unit positioning and implications for injury and performance. J Dance Med Sci. 22: 115-122.

5. Luke A, Kinney S, D'Hemecourt P, et al. (2002) Determinants of injuries in young dancers. Med Probl Perform Art. 17: 105-112.

6. Meeuwisse WH, Tyreman H, Hagel B (2007) A dynamic model of aetiology in sport injury: the recursive nature of risk and causation. Clin J Sports Med. 17: 215-219.

7. Armstrong R, Relph N (2018) Screening tools as a predictor of injury in dance. A systematic review and meta-analysis. Sports Med Open. 4: 33.

8. Gamboa J, Roberts L, Maring, J, et al. (2008) Injury patterns in elite preprofessional ballet dancers and utility of screening programs to identify risk characteristics. J Orthop Sports Phys Ther. 38: 126-137.

9. Smith P, Gerrie B, Varner K, et al. (2015) Incidence and prevalence of musculoskeletal injury in ballet. A systematic review. Orthop J Sports Med. 3: 1-9.

10. Nilsson C, Leanderson J, Wykman A, et al. (2001) The injury panorama in Swedish professional ballet company. Knee Surg Sports Tramatol Arthrosc. 9: 242-246.

11. Kiesel K, Plisky P, Voight M (2007) Can serious injury in professional football be predicted by a preseason functional movement screen. N Am J Sports Phys Ther. 2: 147-152.

12. Armstrong R, Brogden C, Milner D, et al. (2018) The Influence of Fatigue on Star Excursion Balance Test Performance in Dancers. J Dance Med Sci. 22: 142-147.

13. Armstrong R, Brogden C, Greig M (2018) The effects of fatigue on Functional Movement Screening Performance in dancers. Med Probl Perform Art. 33: 213-219.

14. Filipa AR, Smith TR, Paterno MV, et al. (2013) Performance on the Star Excursion Balance Test predicts functional turnout angle in pre-pubescent female dancers. J Dance Med Sci. 17: 165-169.

15. Hutt K, Redding E (2014) The effect of an eyes-closed dance specific training program on dynamic balance in elite preprofessional ballet dancers: a randomized controlled pilot study. J Dance Med Sci. 18: 3-11.

16. Novaco R (1975) Dimensions of anger reactions. University of California, Irvine, California.

17. Biehl B, Landauer A (1975) Das Profile of Mood States (POMS) Mannheim: Universität.

18. Beck AT, Steer RA (1987) Beck Depression Inventory Manual. Psychological Corp, Harcourt, Brace, Jovanovich, Toronto, Canada.

19. Mechelen W, Hlobij H, Kemper HC (1992) Incidence, severity, aetiology and prevention of sports injuries. A review of concepts. Sports Medicine. Aug 14: 82-89.

20. Enoka RM, Dachateau J (2008) Muscle fatigue: what, why and how it influences muscle function. J Physiol. 568: 11-23.

21. Murgia C (2013) Overuse, tissue fatigue, and injuries. J Dance Med Sci 17: 92- 100 
22. Liederbach M, Compango JM (2001) Psychological aspects of fatigue-related injuries in dancers. I Dance Med Sci 5: 116-120.

23. Kellis E, Kouvelioti $V(2009)$ Agonist versus antagonist muscle fatigue effects on thigh muscle activty and vertical ground reaction during drop landing. J Electromyogr Kinesiol 1: 55-64.

24. Semenick D (1990) Tests and measurements: the T test. National Strength and Conditioning Association Journal 12: 36-37.

25. Wyon M, Redding E, Abt G, et al. (2003) Development, reliability, and validity of a multistage Dance-specific Aerobic Fitness Test (DAFT). I Dance Med Sci 7: 80-84.

26. Steinberg N, Hershkovitz I, Peleg S, et al. (2013) Morphological characteristics of the young scoliotic dancer. Phys Ther Sport 14: 213-220.

27. Butler RJ, Plisky PJ, Southers C (2010) Biomechanical analysis of the different classifications of the functional movement screen deep squat test. Sports Biomech. 9: 270-279.

28. Kiesel KB, Pilsky PJ, Butler RJ (2011) Functional movement tests scores improve following a standardised off-season intervention programme in professional football players. Scand J Medicine Sci Sports. 21: 287-292.

29. Schoenfeld BJ (2010) Squatting kinematics and kinetics and their application to exercise performance. I Strength Cond Res. 24: 3497-3506.

30. Armstrong R, Brogden C, Milner D, et al. (2018) Functional Movement Screening as a Predictor of Mechanical Loading and Performance in Dancers. I Dance Med and Sci. 22: 203-208.

31. Dozzi PA, Winter DA (1994) Biomechanical analysis of the foot during rises to full pointe: Implications for injuries to the metatarsal-phalangeal joints and shoe redesign. Kinesiology and Medicine for Dance. 1: 1-11.

32. Nattiv A, Loucks AB, Manore MM, et al. (2007) American College of Sports Medicine position stand. The female athlete triad. Med Sci Sports Exerc. 39: 1867-1882.

33. Mountjoy M, Sundgot-Borgen J, Burke L, et al. (2014) IOC Consensus Statement. Beyond the Triad - RED-S in sport. Br J Sports Med. 48: 491-497

34. Benson JE, Gillien DM, Bourdet K, et al. (1985) Inadequate nutrition and chronic calorie restriction in adolescent ballerinas. Sportsmed. 13: 79-90.

35. Bonbright JM (1989) The nutritional status of female ballet dancers 15-18 years of age. Dance Res J 21: 9-14.

36. Maron BJ, Doerer JJ, Haas TS, et al. (2009) Sudden deaths in young competitive athletes: analysis of 1866 deaths in the United States, 1980-2006. Circulation. 119: 1085-1092.

37. Gray G (1995) Lower Extremity Functional Profile. Adrian, Ml: Wynn Marketing

38. Hertel J, Braham R, Hale S, et al. (2006) Simplifying the star excursion balance test: analyses of subjects with and without chronic ankle instability. J Orthop Sports Phys Ther. 36: 131-137.

39. Gribble P, Hertel J (2003) Considerations for normalising measures of the Star Excursion Balance Test. Meas Phys Educ Exerc Sci. 7: 89-100.

40. Batson G (2010) Validating a Dance-specific screening test for balance. Med Probl Perform Art. 25: 110-115.

41. Crotts D, Thompson B, Nahom M, et al. (1996) Balance abilities of professional dancers on select balance tests. J Orthop Sports Phys Ther. 23: 12-17.

42. Cook G, Burton L, Kiesel K, et al. (2010) Movement Functional Movement Systems: Screening, Assessment, Corrective Strategies. On Target Publications, Santa Cruz, California.

43. Lee L, Reid D, Cadwell J, et al. (2017) Injury incidence, dance exposure and the use of the movement competency screen (MCS) to identify variables associated with injury in full-time pre-professional dancers. Int J Sports Phys Ther. 2: 352-370.
44. Remvig L, Flycht L, Christensen KB, et al. (2014) Lack of consensus on tests and criteria for generalised joint hypermobility, Ehlers-Danlos syndrome: hypermobile type and joint hypermobility syndrome. Am J Med Genet A. 164a: 591-596.

45. Armstrong R (2018) Relative joint contribution to joint hypermobility: The need for careful consideration of lumbar flexion. Int I Sports Phys Ther. 13: 676-686.

46. Castori M, Tinkle B, Levy $H$, et al. (2017) A framework for the classification of joint hypermobility and related conditions. Am J Med Genet Part C Semin Med Genet 175C: 148-157.

47. Armstrong R, Greig M (2018) The Beighton Score as a predictor of Brighton Criteria in sports and dance. Phys Ther Sport. 32 145-154.

48. Grahame R, Bird HA, Child A (2000) The revised (Brighton 1998) criteria for the diagnosis of benign joint hypermobility syndrome (BJHS). J Rheumatol. 27: 1777-1779. 